the mildest attack of influenza,-have we not felt a sort of wandering of our thoughts when we ought to have been healthily sleeping? Have we not found ourselves dwelling on fantastic images, and weaving curious combinations? Have we not felt the occasional involuntary start, or the uncontrollable twitching of some muscle? Have we not, in fine, found that the central, regulating, coordinating agent, that by which our thoughts are elaborated, our ideas conceived, and by which our will exerts its power, has passed from a condition of vigour to one of feeble and uncertain action? And have we not found, as our anxiety has ceased, our work diminished, as our food has been better assimilated, and, in fact, as the nutrition of the brain has improved, that these symptoms have disappeared, and that the normal vigour has returned to the organ of our thought, our intellect, and our will?

And it is by studying these phenomena in their early stages, or their slight manifestations, by watching the steps which mark the passage from health to disease, and from disease back to health, that we gain an insight into their pathology, and the clearest indications as to their treatment.

But in referring to the cases in which this perverted function of the brain occurs, I would distinctly guard my hearers against a hasty generalisation as to its causes or its treatment. It would be far beyond the scope of this lecture for me to attempt to define the peculiarities of delirium as caused by an inflammation of the brain, and of that which results from a mere functional disturbance. My object has been rather to show that, in the majority of cases, the phenomenon is due, not to inflammatory change, but to faulty nutrition, the result of a poisoned state of the blood, or an impairment of the general circulation, or of both these causes combined ; and that, in our treatment, we should direct our efforts to the relief of the general malady, and not specifically to the symptom itself.

[To be continued.]

A Recent Invention. The Graduated Compression Suspensory Bandage is designed for the relief, prevention, and cure of the various diseases connected with or in relation to the spermatic cord, the testes, and the envelopes. This bandage, invented by Dr. G. Miliano, of New York, has been so constructed and arranged as to make equal pressure upon the whole surface of diseased testes and their envelopes. The pressure can be graduated at the pleasure of the surgeon or the wearer, according to the circumstances of the case, by drawing sufficiently upon the braids so as to contract the bandage and compress the disease; then crossing them at the back of the scrotum, at the perineum, and tying them in front under the penis. (American Medical Times.)

Inside A Monitor. Only think of the sanitary prospects of eighty or a hundred men shut up in a submerged iron encasement, with only about sixtyfive cubic feet of air-space to each person, and that sepulchral atmosphere unchanged, except by the very imperfect process of "blowing" a feeble current from the "turret." According to our own rough estimate, each man during battle, or in a sea at all rough, when scuttles and hatches must be closed, would receive less than two cubic feet per minute of fresh air for respiration. Add to this the inevitable humidity and the excessive heat and darkness of the monitors, and you have the elemental and inevitable causes of a fearfully high invalid-rate. (American Med. Times.)

\section{Soriginal Communications.}

\author{
A CASE OF MANIA, WITH ALBUMINURIA, \\ CURED BY THE ROMAN BATH.
}

By C. L. Robertson, M.D.Cantab.; Medical Superintendent of the Sussex Lunatic Asylum, Hayward's Heath ; Editor of the Journal of Mental Science.

M. W. (No. 720) was admitted at Hayward's Heath on February 23rd, 1863.

History. He was married, aged fifty ; was coachmaker at the Brighton railway works; a man of intemperate habits. He was stated to have shown symptoms of mental disease for a twelvemonth, with a tendency to suicide. There was no hereditary taint.

State on admission. a. Bodily. He was very weak. The tongue was furred and tremulous; the whole frame in a state of tremor. He was restless, and did not sleep. b. Mental. The mind was quite confused; he was unable to understand or answer questions. There was difficulty of articulation. He was unable to tell his name; and was disposed to be destructive and dirty.

February 25. Want of sleep and restlessness continued. He was very nervous and tremulous. Pulse feeble, 90 ; pupil contracted. He ate slops. He was ordered to have a glass of whisky at bed-time, and to be packed in the wet sheet for two hours, with two cold pails afterwards.

March 2. He had improved rather under the treatment; pulse 72 ; tongue cleaner; pupils contracted. The mind was incoherent; memory deficient. He was very restless-taking down the pictures; and was disposed to be dirty in his habits.

March 18. He was not so well. Pulse 120 ; face pale; surface cold. Restlessness increased; he was incoherent and noisy. The packing and cold pails were omitted, and $3 j$ of the sedative mixture* ordered to be given at bed-time, and he was directed to continue the whisky and extra food (chops, porter, and ordinary diet), of which he ate well; and to have an occasional warm bath for half-an-hour at bed-time.

May 10. He had lost ground; the restlessness and incoherence continued. He was noisy at night; his habits were dirty; he was feebler. Edema of the legs had set in. The urinet was found laden with albumen, abundant in quantity, specific gravity 1025 , clear, no deposit. The heart was healthy; pulse 110. He was rambling in his conversation; he spoke also of his strength and ability, and that he would build me a carriage, and provide four horses for it, and drive it himself. He was very troublesome, secreting things, etc. He was ordered to have the Roman bath at $150^{\circ}$; to omit the sedative mixture. He was so feeble that he could hardly stand. He had to be carried to the bath. The skin acted feebly; pulse 70, on his return.

May 21. The Roman bath was continued twice a week at $170^{\circ}$. The skin acted better. He was still very feeble. The cedema of the legs was less. His mind was no better; he had delusions, and was incoherent. The albumen was less in quantity.

June 17. He was in every way better. His conversation was more rational. He was gaining strength daily. He still entertained rather an exaggerated

* The following is the formula of the sedative mixture. R. Tincturæ digitalis, tincturæ cannabis Indicæ, liquoris opii (Taylor), turæ digitalis, tincturæ cannabis Indicæ, liquoris

ætheris chlorici, singulorum unciam. Dose 3 ss to $3 \mathrm{j}$.
+ Unfortunately, the urine was not microscopically examined. 229 
idea of his ability and strength, and had a propensity to secrete and collect trash as before. He was ordered to continue the Roman bath twice a week, and to go to the carpenter's shop. The odema of the legs was quite gone. His appetite was hearty. Albumen was slightly present only.

October 5. A steady improvement had taken place. There had been no trace of albumen for some weeks in the urine. He was convalescent. The mind was clear and rational. He worked steadily in the carpenter's shop, and was allowed to go about the premises alone, satisfied with his position and care, and prospect of discharge.

November 30. He was discharged on trial for a month. During the month, he came to Hayward's Heath to ask for a Roman bath. I found him sound in mind and body, and working for the Brighton Railway Company, in their carriage factory, at thirtythree shillings a week.

December 30 . He was discharged cured.

Remarks. The therapeutic uses of the Roman bath have yet to be studied. I believe them to be very great. Of its curative power in the early stages of phthisis I have had several examples, and I can confirm all that Dr. Leared reports of its action in the early stage of that disease. I long to see the Roman bath fairly tried in zymotic diseases. I believe, if used at sufficiently high temperatures $\left(170^{\circ}-200^{\circ}\right)$,
that the results will astonish us all. If anything ever can cure hydrophobia, it will be the Roman bath, at $200^{\circ}$, continued for many hours.

Yet, strange to say, although three years have elapsed since it was fairly and fully brought to the notice of the profession by Mr. Erasmus Wilson, and although the public are building baths, and using them eagerly and ignorantly, no London hospital has thought it worth while to add this potent agent to its armoury. The Newcastle Infirmary, and the Sussex and Devon Lunatic Asylums, are the only hospitals in England (so far as I know) provided with a Roman bath.

In the Journal of Mental Science for July 1861 I gave an account of the Roman bath at Hayward's Heath. A similar bath, capable of accommodating six bathers at a time, can be built for $\$ 150$ to $£ 200$ complete. The cost of heating it is about one shilling a day. In the same journal, for July 1862, I published some cases of melancholia (with refusal of food) successfully treated by the Roman bath, and I have since then regularly used the bath in my practice at Hayward's Heath.

In the case above recorded, I have little doubt that the Roman bath saved the patient's life and restored him to reason. He steadily lost ground until he began its use; the delusions increased; the bodily health gave way; œdema of the limbs set in, and he was so weak that he had to be carried to the bath, and could hardly stand when he came up from it. In six weeks he was at work at his trade, and in six months he was discharged from the asylum sound in mind and body, and able to earn a comfortable living. This cure was the only possible result which I did not foresee. I thought first that the case was tending to permanent dementia; then it looked as if general paresis of the insane would be the end; then it seemed as if he were to die from dropsy and albuminuria. I cannot but think that the Roman bath was the agent which rescued him from all these perils, and restored him to health of mind and body. The
danger which awaits him is a recurrence of the disease, should he revert to his intemperate habits.

Socrates was the son of a midwife, and himself practised the art of midwifery.

\section{Cramsactions of ageramthes.}

SHROPSHIRE ETHICAL BRANCH.

CASE OF ARTIFICIAL ANUS IN THE LEFT LOIN : DEATH FOUR-AND-A-HALF MONTHS AFTERWARDS.

By J. R. Humphreys, Esq., Surgeon to the Salop Infirmary.

[Read September 21st, 1863.]

I was requested on June 21st, to see Samuel Davies, aged 31, who had been an out-patient of mine at the Infirmary for some time, suffering from a tumour of the rectum, diagnosed to be malignant.

The commencement of his illness he dated about twelve months previously, when he experienced a difficulty in passing his motions; this increased, and about two months since he lost all control over his sphincter. I did not see him for some weeks, and when I visited him on Sunday the 21st, he told me that he had been suffering much since he saw me last both night and day, he had been most of his time in bed, and that nothing whatever had passed from his bowels for three weeks. His belly was enormously distended. On passing the finger into the rectum, it came into contact with the tumour, which was hard and of considerable size ; in fact, the bowel was completely blocked up. The poor fellow was in great agony, and begged me to do what I thought proper to relieve him. I explained to him the nature of the obstruction, and what I proposed for his relief; viz., opening the bowel in the left loin. He readily assented to it, and that afternoon I proceeded to the operation,

He was put under chloroform by my friend Mr. W. Eddowes, the house-surgeon of the Infirmary. An incision about four inches long was made in the left loin, midway between the short ribs and the ridge of the ilium; the skin, cellular-tissue, fasciæ, and muscles were divided in turn, and the descending colon reached behind the peritoneum; the bowel was secured by two ligatures at top and bottom, and opened for about an inch and a half long between them; a great quantity of gas immediately rushed out, followed by a stream of dark coloured fæces, which continued for some considerable time; the ligatures of the bowel were passed through the respective edges of the external opening, so as to bring the outlet of the bowel continuous with the skin; some brandy and water was given to the patient, a moist flannel placed over the wound, and a towel pinned round his waist; he was put to bed, and expressed himself greatly relieved. A marked change was noticed in his countenance, which was less anxious, and showed clearly that he had been relieved of much suffering.

June 22nd. He passed a comfortable night. A copious discharge of wind and fæces had escaped from the opening during the night, and the belly was softer and more natural. He had taken ample nourishment, and expressed himself in grateful terms for the relief which he had experienced.

June 25th. I found him dressed, and lying on the couch downstairs. He had passed a comfortable night, and took solid food. The vent was acting well.

July 10th. As the opening in the loin closed up more rapidly than I wished, I passed a full sized rectumbougie into the bowel, and afterwards injected a
pint and a half of cold water into it with an elastic enema apparatus ; by this means the bowel was emptied much more effectually and more comfortably. I instructed his nurse to do the same thing every morning. He was able to take all kinds of food; dressed himself daily, and walked about the house. He was 